\title{
Entre palavras e objetos: Cultura material e Abolicionismo no Vale do Paraopeba/MG (1840-1888)
}

\author{
Between words and artifacts: \\ Material culture and Abolitionism in the Vale do Paraopeba/MG \\ (1840-1888)
}

\section{Claudia Eliane Parreiras Marques Martinez ${ }^{1}$}

\section{RESUMO}

O objetivo deste artigo é analisar a cultura material do professor de primeiras letras, advogado, solicitador de capelas e resíduos, curador de escravos Manoel Bernardes da Cunha Cassão, falecido em 1877, na cidade de Bonfim. Com base em seu inventário post-mortem, de um banco de dados composto por 450 documentos cartorários e outras fontes, foi possível descortinar questões pertinentes à oscilação das fortunas, à posse de escravos e terras, a relação entre o interior de Minas Gerais e a Corte do Rio de Janeiro e, principalmente, o significado e a simbologia de possuir alguns artefatos, considerados, na época, sofisticados, exóticos e luxuosos. Para a realização deste trabalho, foi necessário recorrer a alguns pressupostos da História Social e da Micro História. Tendo como referência o conceito de "excepcional normal", de Edoardo Grendi, problematizou-se, a partir das pistas e vestígios deixados por Cassão, como os objetos e os livros localizados em sua moradia, bem como sua atuação social e política, constituíram, ao mesmo tempo, desvio e regra na sociedade oitocentista.

Palavras-chave: Três. Palavras. Chave.

\section{ABSTRACT}

This paper seeks to analyze the material culture of teacher of first letters, lawyer, solicitor of chapels and remainders, curator of slaves Manoel Bernardes da Cunha Cassão, deceased in 1877, in the city of Bonfim. Based on his post-mortem inventory, from a database consisting of 450 documents and other sources, it was possible to uncover issues related to the oscillation of fortunes, the possession of slaves and lands, the relationship between the inland of Minas Gerais and the Imperial Court of Rio de Janeiro, especially the meaning and symbolism of having some artifacts, considered, at the time, sophisticated, exotic and luxurious. For this article, it was necessary to rely on some assumptions of Social History and Micro History. Taking Edoardo Grendi's concept of "normal exceptional" as a reference, it was problematized, from the clues and vestiges left by Cassão, how the objects and books located in his dwelling, as well as his social and political performance, meant, at the same time, deviation and rule, in the nineteenth-century society.

Keyword: Material culture. Intellectual culture. Post-mortem inventory. Abolitionism. Vale do Paraobeba (MG).

1 Doutora em História. Professora Adjunta do Departamento de História - Universidade Estadual de Londrina/PR. 


\title{
Primeiras palavras
}

Em uma manhã de 1858, no Vale do Paraopeba, precisamente na Vila de Bonfim, o "professor d'instrução primária" Manoel Bernardes da Cunha Cassão lecionava para algumas crianças e adolescentes. Ensinava a eles as primeiras lições de latim, português e história. Usava como referência a centena de livros que compunham sua biblioteca. ${ }^{2}$ Nesse mesmo ano, outras evidências ${ }^{3}$ históricas revelaram que o dito professor denunciou o escrivão de órfãos da Vila pelos "factos escandalosos" que esse notário supostamente estaria praticando.

\begin{abstract}
Manoel Bernardes da Cunha Cassão, professor d'instrução primária desta Villa, donde é natural, usando do direito concedido no Artigo 74 do Código do Processo Crime vem respeitosamente perante Vossa Senhoria denunciar a Jacintho Brandão de Souza Barros, escrivão de Órfãos deste termo, pelos factos escandalosos que tem praticado nesta Vila, quais as de incontinência pública, embriaguez repetida e dezidia habitual no cumprimento de seus deveres [...] (PROCESSO DE RESPONSABILDADE, CSO 12 (277).
\end{abstract}

Na mesma década de 1850, encontramos Cassão atuando como advogado dos "bens de pouca monta" dos inventários post-mortem do Sr. Joaquim Nunes de Araújo e do Sr. Feles Pereira da Rocha. ${ }^{4}$ Em 1873, assumiu o cargo de "Solicitador de Capellas e Resíduos", 5 o que indica sua participação direta na administração jurídica do Município de Bonfim do Paraopeba. Além disso, continuava atuando ativamente como advogado e curador de escravos condenados à forca, como consta do processo crime de 1875. Nesse documento, o referido curador solicita à Corte do Rio de Janeiro, por meio do Ministério da Justiça, a comutação da pena de morte imposta ao escravo Rofino. A Princesa Isabel atendeu ao pedido de Cassão e "aliviou" a sentença para "Galés Perpetua". 6

Quem teria sido Cassão e qual a importância social e política que ele teve no interior da Província de Minas Gerais, nas quatro últimas décadas do período escravista? Por que elegê-

\footnotetext{
${ }^{2}$ Essas e todas as informações sobre a biblioteca e a cultura material de Manoel Bernardes da Cunha Cassão citadas neste artigo foram retiradas de seu inventário post-mortem. A abertura do inventário se deu em 17 de agosto de 1877. Ver o documento original em: Arquivo Municipal de Bonfim/Minas Gerais, Inventário post mortem, CPO 17 (21), 1877.

${ }^{3}$ As ideias desenvolvidas neste trabalho estão em consonância com as teorias e metodologias de Carlo Ginzburg (1989) e Jacques Revel (1998), principalmente.

${ }^{4}$ Arquivo Municipal de Bonfim/Minas Gerais, Inventário post mortem, CPO 07 (8), 1858, e CPO 73 (15), 1859.

${ }^{5}$ Ver a informação no Almanaque Administrativo, Civil e Industrial de Minas Gerais, 1873. Para mais esclarecimentos sobre a atuação de um "Solicitador de Capellas e Resíduos" na administração jurídica do Império do Brasil, ver o último item deste artigo.

${ }^{6}$ Arquivo Municipal de Bonfim/Minas Gerais, Processo Crime, CSO 29 (565).
} 
lo dentre as centenas de inventários post-mortem e processos crimes analisados no Arquivo Municipal de Bonfim? ${ }^{7}$ Por intermédio de seus objetos, bens e propriedades, é possível compreender aspectos e nuances da vida desse homem, seus hábitos e estilos? O conceito de "excepcional normal" 8 poderia ser aplicado a Cassão, para compreender sua atuação singular naquela sociedade? Como e de que forma esse homem "excepcional" (con)vivia com seus pares, (inter)agia dentro da "(a)normalidade" das esferas política e social de seu tempo? Um tempo marcado pela escravidão e por seu inevitável declínio, pela crescente demanda por terra e pela valorização gradual de alguns objetos do cotidiano. Enfim, um tempo pautado pela busca de diferentes alternativas de trabalho ou sua reestruturação frente à realidade política e econômica que se impunha definitivamente no Vale do Paraopeba, em Minas Gerais, e no Brasil.

A cultura material de Manoel Bernardes da Cunha Cassão, localizada em seu inventário post-mortem, é digna de nota, pois apresenta singularidades notáveis em relação à de seus contemporâneos. ${ }^{9}$ Sua complexa biblioteca, composta por quase cem livros, permite pensar sobre a cultura intelectual desse homem oitocentista. Entre as obras dispostas nas "estantes grandes para livros", encontram-se exemplares sobre filosofia, literatura, física, história, medicina e farmácia, além de tratados, ordenações, leis etc.

O mobiliário sofisticadíssimo de sua moradia era composto por cantoneiras de mármore, cadeiras finas, marquesas, entre outros móveis. Na sala de estar (ou na sala de jantar?), encontramos um piano avaliado em $200 \$ 000$, valor esse com que se poderia comprar um "boi gordo" ou uma "escrava para a realização de serviços domésticos". Olhando por entre as "janelas envidraçadas" de sua casa, identificamos distintos instrumentos musicais, como uma flauta e um flautim. Encontramos, ainda, mala de viagem, bolsa de caça, máquinas de bater ovos, máquina de fazer água gasosa e demais artefatos que em nada se pareciam com os toscos bancos de madeira e catres localizados nas centenas de casas, fazendas e sítios que pudemos visitar figurativamente ao longo da pesquisa.

É importante destacar que as definições de riqueza, ostentação, luxo, sofisticação, bonança, "excepcionalidade" (bem como o seu inverso) só puderam ser pensadas e problematizadas com base na comparação e na análise conjunta de outros tantos inventários. ${ }^{10} \mathrm{O}$ exame da excepcionalidade ou da regra pressupõe comparações, analogias. Por isso, antes de mergulharmos na vida de Cassão de forma vertical e profunda, verificando sua

\footnotetext{
${ }^{7}$ Em 1996, fui contratada pela Prefeitura Municipal de Bonfim para organizar o acervo cartorial da Comarca. O trabalho realizado no acervo cartorário do Município de Bonfim, entre 1996 e 1998, culminou na sistematização de mais de 5.000 documentos, codificados e catalogados com seus respectivos fundos, natureza, nomes, datas, origem e procedência. Com base nesse trabalho é que foi possível criar o Arquivo Municipal de Bonfim, que se encontra, hoje, localizado na Casa de Cultura da mesma cidade.

${ }^{8}$ A ideia de "excepcional normal" foi proposta por Edoardo Grendi. O conceito será abordado de forma mais detida na última parte deste artigo.

${ }^{9}$ Inventário post-mortem, op. cit., 1877.

${ }^{10} \mathrm{Em}$ estudo anterior, desenvolvido em nossa tese de doutorado, utilizamos 761 documentos com outros propósitos e problemáticas. $O$ estudo que ora se apresenta é fruto de novas reflexões e/ou apontamentos feitos na tese, mas que naquele momento não puderam, em razão dos prazos, ser aprofundados ou trabalhados. Ver: Martinez (2014).
} 
cultura material e aspectos de sua intelectualidade, foi necessário compreender como eram constituídos os bens e os artefatos de seus pares e de que modo a sociedade estava organizada hierarquicamente.

O trabalho que se apresenta aqui, portanto, baseia-se e situa-se no diálogo historiográfico e metodológico proposto pela História Social e pela História Cultural. Por meio dessas discussões, que se prolongam há mais de vinte anos no Brasil, buscou-se averiguar como Manoel Cassão se inseria na sociedade e na esfera política do Vale do Paraopeba. Para tanto, foi necessário compreender como os distintos grupos sociais - A, B e C - estavam economicamente dispostos. Do mesmo modo, foi preciso entender a composição das riquezas desses segmentos da sociedade, destacando, por exemplo, quais tipos de bens e objetos eram mais ou menos valorizados na sociedade do Vale do Paraopeba. Enfim, tornou-se indispensável pensar essas questões, ou seja, quais eram os referenciais de riqueza, pobreza, luxo e sofisticação material e intelectual vigentes naquela sociedade, nas décadas finais do período escravista.

Somente após as análises que envolvem a roda da fortuna e os artefatos dos diferentes estratos sociais, o leitor poderá mergulhar na vida material e cultural de Cassão. Questões relativas à sua atuação política e social virão à tona, deixando transparecer seu trabalho como advogado dos pobres, curador dos escravos, "Solicitador de Capellas e Resíduos" e de tenente. Também se revelará sua atividade como leitor assíduo, caçador, apreciador de instrumentos musicais e proprietário de peças e objetos inusitados.

Para a realização deste trabalho foi necessário, ainda, recorrer a alguns pressupostos da Micro História. ${ }^{11}$ Em razão disso, mudamos o foco da análise, isto é, passamos a usar uma "lente" poderosa, que permitiu "enxergar" o detalhe e, assim, decifrar os vestígios e sinais deixados por Cassão. Ainda que de forma fragmentada e inconclusa - como, aliás, é o trabalho do historiador -, foi possível perceber de que modo a parte (a vida do homem) conectava-se e ajustava-se ou não ao todo (a sociedade).

Cabe destacar, por fim, que tais questionamentos só foram passíveis de observação e crítica graças ao exame de um banco de dados composto por 450 inventários post-mortem e outros tantos documentos complementares. É da história dessas transformações materiais e de algumas ideias políticas e econômicas vigentes no Brasil Império que trata este trabalho.

\section{O pêndulo da fortuna e a cultura material da sociedade}

Um dos pontos que distingue a historiografia contemporânea dos estudos "tradicionais" é o fato de que a cultura material deixou de ser compreendida como um "rol de artefatos" e

${ }^{11}$ Como já apontado em nota de rodapé anterior, este artigo tem como referência teórico-metodológica as ideias propostas, principalmente, por Carlo Ginzburg, Jacques Revel e Edoardo Grendi. 
passou ser analisada em simbiose com a sociedade que a criou, com a economia que a produziu, com o mercado que a distribuiu e com a cultura que permitiu sua existência estética, morfológica e funcional. ${ }^{12}$ A partir da década de 1990, os artefatos passaram a ser discutidos, no tempo e no espaço, como invenções e criações de grupos sociais nos quais homens e mulheres de diferentes etnias estão inseridos. ${ }^{13}$

Outro ponto que caracteriza a abordagem da cultura material na contemporaneidade está relacionado à tipologia das fontes. Além dos artefatos preservados dentro e fora das instituições museais, as fontes escritas (inventários, testamentos, relatos de viagem, notas de compra etc.) e as fontes visuais (fotografias, pinturas e imagens de objetos) passaram a ser igualmente utilizadas. Embora a existência concreta do artefato seja importante, o estudo da cultura material pode (e deve) ser realizado também por meio das fontes escritas que os identificam, qualificam, denominam, enumeram e descrevem.

Com a peça "em mãos", é evidente que muitos problemas relacionados à morfologia, à estética ou à "cultura tecnológica" poderiam ser imediatamente solucionados. No entanto, o objeto autônomo, assim como aqueles pertencentes às coleções - relógios, armas, joias, vestuário... -, acaba por constituir um modelo abstrato de si mesmo; transforma-se em documento "descolado" de seu ambiente histórico. Por tudo isso, é pertinente que os artefatos sejam apreendidos em "situação" e por meio dos vários "sistemas" de que fazem parte (MENESES, 2007, p. 14). Segundo esse propósito, os inventários post-mortem constituem uma fonte modelar. Moradia, vestuário, trabalho, lazer, interior doméstico, religiosidade, produção e circulação; localização, temporalidade, espacialidade e qualificação são estudados em conjunto e dentro do contexto de criação, existência, troca e funcionalidade. Como nos lembra Meneses (2007), esse tipo de documento é muito proveitoso para o historiador da cultura material.

Uma das vantagens que o inventário assegura é fornecer elementos para tratar, não de coisas isoladas, mas de conjuntos - o que os avizinha, na medida do possível, de sistemas, sem os quais um simples rol de artefatos se revelaria muito limitado, incapaz de produzir as inúmeras inferências que só os sistemas permitem: não apenas as diversas

\footnotetext{
${ }^{12}$ Como exemplos de abordagem clássica ou tradicional podem-se citar trabalhos que tinham como objetivo apresentar a história do mobiliário, das louças, das joias etc., elencando e dando ênfase apenas às suas características morfológicas e taxonômicas. Um modelo desse tipo de abordagem pode ser encontrado nos estudos desenvolvidos por Gustavo Barroso (1947). Por historiografia clássica entendem-se, também, os trabalhos produzidos, sobretudo, na primeira metade do século XX, como aqueles realizados por Alcântara Machado (1929), Gilberto Freyre (1933; 1936) e Sérgio Buarque de Holanda (1957). É preciso lembrar que a historiografia clássica não tinha a intenção explícita de investigar a cultura material. Por isso, tais autores e obras tornaram-se fonte de pesquisa inspiradora em decorrência da natureza de seus trabalhos, mas não um referencial metodológico e conceitual.

${ }^{13}$ Uma das primeiras instituições brasileiras a sistematizar e a constituir um significativo núcleo de reflexão teórica e metodológica sobre cultura material foi o Museu Paulista. Sob a direção do professor Ulpiano Toledo Bezerra de Meneses, foi inaugurada, em 1993, a Nova Série dos Anais do Museu Paulista. Ver: Meneses (1993).
} 
categorias, suas quantidades, mas também a qualidade são atributos que enriquecem as conexões e os subconjuntos que podem ser identificados. Além disso, esses conjuntos de bens arrolados situam-se num ponto de inflexão no circuito da vida social do artefato: aquele em que ele sai de um uso cotidiano e costumeiro para relançar-se em novo ciclo. Daí o caráter de 'estado de coisas', de síntese, de balanço, de avaliação, que caracteriza os inventários post-mortem. A adjetivação e os atributos descritivos são extremamente ricos de informações para identificar valores (monetários, pragmáticos e afetivos), hierarquias, preferências, significações. (MENESES, 2007, p. 15).

Diferentemente dos documentos atuais, nesse tipo de fonte cartorária (dos séculos XVI ao XIX), encontra-se descrito tudo, ou melhor, quase tudo, que existia dentro e fora das moradias urbanas, das fazendas e daquelas construções situadas nos subúrbios das vilas e cidades. Os inventários têm um padrão que se repete ao longo de décadas e, com raras exceções, neles não se menciona o valor monetário de cada objeto, animal ou escravo.

Além disso, relacionam e descrevem todos os bens com adjetivos e informações qualitativas e quantitativas: "uma mesa velha e pequena, duas xícaras inglesas de asa quebrada, um oratório com seis imagens, duas estampas, duas coroas e dois resplendores de prata". Por vezes, trazem ainda a localização dos objetos no interior da moradia, o que permite conhecer melhor a divisão interna das casas. Sabe-se, por exemplo, que, em 1866, na Vila de Bonfim, na casa de Dona Josefa Evangelista da Conceição, localizada na Rua das Flores, existiam "um oratório na sala e um relógio velho na parede". ${ }^{14}$ Também é possível ter conhecimento da posição exata das casas, descritas com a localização das ruas, nomes dos vizinhos, ou, ainda, com referências espaciais - por exemplo: "no Largo da Matriz", "em frente à porta da igreja", "casa pequena do lado de cima do chafariz com quintal". ${ }^{15}$

Os inventários post-mortem revelam, ademais, o nível de vida dos diferentes grupos da sociedade. A análise quantitativa e serial permite conhecer em detalhes como os bens materiais estavam alocados nos distintos estratos sociais. Tal abordagem é de suma importância, porque indica, por exemplo, qual era a condição socioeconômica dos envolvidos, e não só de Manoel Bernardes da Cunha Cassão, mas também de seus pares - homens e mulheres com os quais conviveu no século XIX. Saber como e onde Cassão localizava-se na pirâmide social foi o primeiro passo dado para compreender sua situação socioeconômica.

\footnotetext{
${ }^{14}$ Arquivo Municipal de Bonfim/MG, CSO, 20 (12), 1866.

${ }^{15}$ Arquivo Municipal de Bonfim/MG, CSO, 65(10), 1893; CSO 19 (06), 1895; CSO 65 (07), 1890.
} 
Para tanto, dividimos e classificamos um lote de 450 inventários datados de 1840 a $1888 .{ }^{16}$ O resultado dessa análise apontou que a sociedade inventariada estava estruturada em três grupos distintos: A, B e C. ${ }^{17}$ Tais grupos foram definidos segundo o valor do monte-mor, ou seja, o total da riqueza (bens de raiz, escravos, animais, artefatos, dívidas ativas) calculada em réis.

Antes de definir as características gerais dos três grupos, identificando-os na sociedade em que estavam inseridos, é preciso esclarecer como os dados foram computados. Optou-se por apresentar os valores monetários em réis. Manter a moeda vigente no País, no qual os documentos foram elaborados, é justificável, uma vez que os objetos do cotidiano, os imóveis, os escravos, os animais e as dívidas foram arrolados de forma a priorizar sua participação relativa no total da riqueza.

Dos itens disponíveis nos inventários post-mortem que possibilitam ao pesquisador perceber os referenciais de riqueza, o monte-mor constitui a principal variável. Apesar de não unificar integralmente os membros de um mesmo grupo social, o total da riqueza dá a eles um status econômico compatível com uma análise comparativa.

Dessa maneira, identificam-se como pertencentes ao Grupo A os membros mais ricos da sociedade, em geral donos de grandes propriedades de terra e de escravos. A riqueza particular dos inventariados desse grupo era superior a dez contos de réis (10:000\$000). Embora numericamente inferior, esse estrato social detinha a maior parte dos cabedais. No período escravista analisado (1840-1888), por exemplo, seus componentes conseguiram concentrar, em média, a incrível cifra de $70 \%$ das fortunas analisadas.

O grupo intermediário da sociedade - o Grupo B - concentrou fortunas que variavam de 5:000\$001 a 10:000\$000 contos de réis. Esse setor médio tinha, em relação ao setor A, uma concentração de riqueza de apenas $16,2 \%$ durante o período imperial analisado. Manoel Bernardes conseguiu acumular em vida uma fortuna de pouco mais de sete contos de réis (7:220\$418). Esse é o primeiro indício de que nem sempre os mais ricos conheciam o significado do luxo, da sofisticação e do conhecimento intelectual.

É importante sublinhar que, na segunda metade do século XIX, a sociedade do Vale do Paraopeba era majoritariamente rural; sua economia baseava-se na produção de alimentos, na criação de animais e na produção de tecidos de algodão. Em uma economia de

\footnotetext{
${ }^{16} \mathrm{O}$ recorte cronológico - 1840 a 1888 - justifica-se em razão não só da documentação cartorária disponível, mas porque esse período cobre a vida adulta e produtiva de Manoel Bernardes da Cunha Cassão. Como o período escravista era imprescindível para as análises aqui empreendidas, achamos importante estender a pesquisa até os momentos finais da escravidão no Brasil.

${ }^{17}$ Para chegar à definição dos três grupos - A, B e C -, foram consultados e analisados vários estudos congêneres. O cotejamento desses trabalhos permitiu compor e classificar a sociedade do Vale do Paraopeba em três níveis socioeconômicos, tendo como base sua realidade econômica, ou seja, a de uma economia de abastecimento interno. Para mais informações a respeito da metodologia utilizada, ver: Fragoso (1992); Mattoso (1992); Araújo (2003); Almico (2001); Versiani, Vergolino (2003). Para mais detalhes e esclarecimentos sobre os desdobramentos dessa questão, ver Martinez (2014).
} 
abastecimento interno, os referenciais de riqueza e status econômico, geralmente estavam assentados na posse de escravos e terras, como pudemos constatar em estudos já realizados (MARTINEZ, 2007; 2014). Embora Cassão pertencesse ao Grupo B - em razão do valor de seu monte-mor -, as características materiais e simbólicas de sua fortuna não eram compatíveis com as de seus pares, em termos econômicos.

Já as fortunas do setor menos privilegiado da sociedade ficaram abaixo de cinco contos de réis (5:000\$000). Ainda que materialmente mais pobre, o Grupo C - composto pelos não escravistas, pequenos proprietários de cativos (1 a 3 indivíduos), donos de sítios, fazendas modestas e moradas urbanas mais singelas - totalizava mais de $60 \%$ dos casos analisados. Apesar de numericamente superior, o setor agregou, no período analisado, apenas $13,8 \%$ dos cabedais.

Após a classificação da sociedade em três estratos socioeconômicos, cabe agora compreender quais eram os bens e os objetos que cada estrato possuía e detinha no momento da abertura do inventário post-mortem.

\section{A roda da fortuna: regra e desvio em um mundo sustentado pela escravidão}

O estudo da flutuação da riqueza material ajuda a descortinar aspectos da sociedade, da economia, dos investimentos - em suma, o que era valorizado e desconsiderado na coletividade. Revela também como a fortuna, a pobreza, as necessidades, o luxo e o supérfluo estavam disseminados no cotidiano. Porém, antes de examinar essas questões que envolvem o detalhe e a essência dos aspectos culturais e simbólicos, abordar-se-á como as grandes categorias materiais - bens de raiz, escravos, animais, artefatos e dívidas ativas movimentaram-se ao longo das quatro décadas aqui enfocadas. ${ }^{18}$

A rubrica "bens de raiz" envolve simultaneamente as terras de cultura, campos ou pastos de criar animais, os terrenos urbanos, as casas, os sobrados, as chácaras, enfim, toda a estrutura imobiliária da sociedade. Os "artefatos" contemplam os utensílios profissionais e domésticos, a vestimenta, o mobiliário, os objetos pessoais, os livros, as joias e tudo o mais que compunha o meio íntimo/familiar e também a esfera do trabalho, com suas ferramentas, máquinas e equipamentos. As demais categorias - escravos, animais e dívidas -, por sua própria natureza, não exigem mais explicações quanto a sua concepção. No período imperial os escravos assumiram a liderança, seguidos de perto pelos bens de raiz. Em algumas décadas

\footnotetext{
${ }^{18}$ Para um maior esclarecimento sobre a tipologia dos objetos - bens de raiz, escravos, animais, artefatos e dívidas -, ver o trabalho de Martinez (2014). Nesse estudo podem-se encontrar não só mais informações sobre a metodologia, mas também toda uma bibliografia a respeito da temática.
} 
- 1850 e 1860 -, o elemento servil chegou a representar quase 50\% do patrimônio familiar, enquanto a terra e os imóveis em geral ficaram em torno de $30 \%$.

O número de animais manteve-se estável, com uma média de 5,8\%, perfazendo em alguns momentos, como na década de 1870 , o percentual de $8 \%$. Já os artefatos do cotidiano iniciaram o período de 1840 com uma participação de $17,9 \%$ em réis, chegando ao percentual de $28,7 \%$ no final da escravidão (Tabela 1). Os índices das dívidas ativas, com exceção dos anos 1840, em que apresentaram um índice de 1,5\%, variaram de 4,5\% a 5,9\%.

Em relação aos percentuais das dívidas ativas ${ }^{19}$ e dos animais, nota-se que as cifras relativas a Manoel Bernardes da Cunha Cassão são muito superiores (Tabela 2) às médias encontradas em todas as décadas aqui analisadas. Essas e outras questões a respeito da cultura material e simbólica de Cassão serão avaliadas mais detidamente no último item deste artigo.

Tabela1:

Bens de raiz, escravos, animais, artefatos, dívidas ativas, em réis, Vale do Paraopeba

\begin{tabular}{|l|c|c|c|c|c|c|}
\hline $\begin{array}{l}\text { Tipologia } \\
\text { dos bens }\end{array}$ & $\begin{array}{c}\text { Dívida } \\
\text { Ativa }\end{array}$ & $\begin{array}{c}\text { Bens de } \\
\text { Raiz }\end{array}$ & Escravos & Animais & Artefatos & Monte-mor \\
\hline Décadas & $\%$ & $\%$ & $\%$ & $\%$ & $\%$ & $\%$ \\
\hline $1840 / 49$ & 1,5 & 34,7 & 39,4 & 6,5 & 17,9 & 100 \\
\hline $1850 / 59$ & 5,1 & 26,9 & 48,3 & 4,1 & 15,5 & 100 \\
\hline $1860 / 69$ & 5,8 & 28,4 & 47,5 & 4,3 & 13,9 & 100 \\
\hline $1870 / 79$ & 5,9 & 27,1 & 45,5 & 8,0 & 13,5 & 100 \\
\hline $1880 / 88$ & 4,5 & 33,5 & 29,9 & 6,4 & 28,7 & 100 \\
\hline Média total & 4,6 & 30,1 & 42,1 & 5,9 & 17,9 & 100 \\
\hline
\end{tabular}

Fonte: AMB/MG, inventários post-mortem, 1840/1888

Continuando a análise da roda das fortunas, pudemos constatar que os membros do Grupo A determinavam a política local, disseminavam os novos costumes e, ao mesmo tempo, concentravam em suas mãos as atividades produtivas de maior relevo econômico da região, como a produção de alimentos, fios e tecidos para atender ao mercado interno dos mineiros e ao de distintas partes do Brasil, como a Corte do Rio de Janeiro. Por isso, saber o que possuíam, como adquiriam e investiam seus bens não só esclarece o perfil dos abastados, mas também possibilita constituir um mosaico de relações econômicas, sociais e culturais.

A escravaria compunha de $25 \%$ a $49 \%$ do espólio das famílias mais ricas da sociedade (Ver Anexo 1). Ao comparar esses resultados, nota-se que, embora altos, eram percentuais inferiores aos dos Grupos B e C. Igualmente inferior à verificada nas demais camadas foi a

\footnotetext{
${ }^{19}$ As dívidas ativas referem-se aos créditos que a família do inventariado tinha para receber. Ao contrário, as dívidas passivas referem-se ao que o inventariado devia até o momento da abertura do inventário post-mortem.
} 
participação relativa dos animais. Em todo o período analisado, o gado bovino, o equino e o suíno compuseram $5,3 \%$ do espólio dos membros mais ricos da sociedade. $E$, dentro da categoria dos animais, os ricos investiam mais em bois e cavalos, ficando a criação de porcos relegada aos menos abastados, como se verá na análise dos demais grupos sociais.

O estudo dos inventários indica que os abastados estavam mais dispostos a concentrar sua riqueza em terras, escravos e outras formas de bens, como os artefatos. No entanto, devem-se antecipar aqui alguns pontos que visam a esclarecer a concepção proposta para analisar os artefatos do cotidiano.

Como já salientado, entende-se como artefatos todos os utensílios da casa - móveis, objetos de cozinha, vestimentas, objetos pessoais, joias etc. Os equipamentos, as ferramentas de trabalho, como enxadas, machados, foices, os moinhos, os monjolos, os engenhos de cana, as "trapizongas", ${ }^{20}$ os carros de bois, os teares, as rodas de fiar; enfim, tudo isso compunha o universo dos objetos do cotidiano.

Esse amplo conjunto denominado aqui de "artefatos" constituiu o principal diferencial entre os membros daquela sociedade interiorana. Sempre com cifras superiores a $15 \%$ dos cabedais, os elementos materiais dessa categoria traduzem as várias facetas da riqueza familiar. Decodificando seus múltiplos significados, observa-se, por exemplo, o poder econômico e cultural representado pela posse de determinados objetos (os importados, principalmente). Os dados proporcionam uma dimensão precisa de quanto os elementos dos cabedais oscilaram no tempo, ganhando e/ou perdendo espaço social e importância econômica. Destaque deve ser dado, neste momento, para a década de 1880, na qual os artefatos chegaram a compor 35\% da fortuna do Grupo A.

E como o setor médio da sociedade reagia à roda da fortuna? Ou seja, que tipo de bens e objetos eram privilegiados por esse setor? Como se comportava economicamente em face do sistema escravista? É possível pensar uma definição precisa para esse grupo social? Nem rico, muito menos pobre. Essa é uma das possíveis definições para o setor médio da sociedade, que teve suas fortunas avaliadas entre 5:000\$001 e 10:000\$000 réis. Com menos recursos financeiros que o Grupo A, as famílias da camada intermediária do Vale do Paraopeba chegaram a concentrar, no período escravista, de $25 \%$ a $43 \%$ de seus bens em imóveis. Em relação aos escravos, a realidade encontrada foi surpreendente: de $27 \%$ a $58 \%$ da riqueza estavam alocados nos plantéis, superando, dessa forma, as médias referentes aos mais ricos (só para lembrar, os escravos chegaram a compor de $25 \%$ a $49 \%$ da riqueza do grupo A).

A atitude da camada intermediária frente à pecuária também diferiu muito da dos seus pares mais ricos. No período escravista analisado, os percentuais foram modestos, variando

\footnotetext{
${ }^{20}$ Trapizonga é um equipamento movido a água e utilizado para moer/socar o milho, limpar arroz, moer cana e ralar mandioca. O instrumento de beneficiamento de alimento foi muito utilizado nas fazendas dos séculos XVIII e XIX. Sua descrição foi mencionada nos inventários post-mortem por nós pesquisados no Vale do Paraopeba.
} 
de $3 \%$ a $12 \%$. Diversamente dos membros mais ricos, a camada média vislumbrava nos animais uma fonte de renda e investimentos compatível com suas possibilidades financeiras. Com os animais, podia-se conseguir algum dinheiro, comercializando-os, realizando trocas e até alimentando-se deles em tempos de instabilidade econômica.

Outra característica que difere o Grupo B do primeiro aqui analisado é a forma como interagia com a categoria dos artefatos. Bem mais modestas e com menos capacidade de acumulação de capital, as famílias dessa camada social agregaram a sua composição material cifras que variaram de $2 \%$ a $20 \%$. Não só as cifras chamam atenção, mas também a qualidade, as características e a excepcionalidade de alguns artefatos, como aqueles encontrados no inventário de Cassão, detalhadamente analisado no próximo item. Mais um ponto que o distingue do Grupo B é o investimento em cavalos. Enquanto os membros intermediários da sociedade investiam $7 \%$ de suas riquezas em animais, Cassão disponibilizou um total de18\% de sua riqueza somente em cavalos (Ver Tabela 2).

E como se comportava economicamente o estrato mais numeroso da sociedade inventariada? Em média, o Grupo C nunca deixou de representar $60 \%$ da população catalogada, como já salientado neste artigo. No entanto, seus bens e condições materiais de longe são compatíveis com sua percentagem numérica. Com estilo de vida mais simples, os cabedais e os espólios modestos do Grupo $\mathrm{C}$ eram muito distintos dos de seus adjacentes e rivais econômicos - os Grupos A e B.

Analisando de maneira pormenorizada o patrimônio dos membros mais pobres da sociedade inventariada, descobre-se que o bem mais importante eram seus domicílios. $\mathrm{Na}$ cidade ou no campo, os pequenos sítios ou casebres suburbanos constituíam, às vezes, seu único bem. Os percentuais variaram de $31,7 \%$ a $42,7 \%$ no período escravista, conforme os dados contidos no Anexo 1 demonstram.

Por outro lado, é surpreendente o quanto era significativo para essa camada social possuir um pequeno plantel de escravos. Destaca-se que a riqueza do Grupo $\mathrm{C}$ variou de $270 \$ 000$ a 5:000\$000, o que permitia às famílias adquirir, além de uma pequena propriedade, 1 a 3 escravos.

Os cativos pertencentes ao Grupo C constituíram peça fundamental na composição e na estabilidade familiar. Segundo Auguste Saint-Hilaire (1975), esses escravos trabalhavam na roça, lado a lado com seus proprietários. Ajudavam as mulheres no processo de fiação e tecelagem, bem como a cuidar da horta, dos porcos, das galinhas e dos demais animais domésticos. Da mesma forma, auxiliavam os homens a apartar as vacas leiteiras e a ordenhar o leite; por vezes, eram vistos vendendo o excedente da produção doméstica nas vilas e cidades próximas às fazendas e aos sítios. 
Muitos inventários dessa camada social referem-se a mulheres solteiras. A presença, nos domicílios, de escravas fiandeiras, bem como de teares e rodas de fiar, era recorrente, como se pôde constatar em trabalho realizado anteriormente (MARTINEZ, 2014). Vários documentos localizados no Arquivo Municipal de Bonfim indicam a presença da mão de obra feminina. Com base em tais dados, é possível avaliar a importância, para o segmento social em questão, de adquirir um(a) escravo(a). Afinal, essa camada social vivia de seus serviços e dos poucos recursos que lhe eram destinados em vida.

Menos que os escravos, mas igualmente importantes para a sobrevivência das famílias, os animais tiveram um peso substantivo na vida dos menos remediados. No período escravista analisado, os animais representaram uma quantia modesta, não ultrapassando $8 \%$ do espólio. O mesmo pode ser dito sobre os "artefatos" do cotidiano. Com menos condições materiais, as famílias do Grupo $C$ foram as que menos investiram nesse tipo de ativo. Preferiam, ou não lhe restava alternativa, assegurar o pouco que tinham em bens mais tradicionais, como imóveis, escravos e animais.

Da mesma forma, não foram significativas as cifras encontradas para as dívidas ativas. Numa sociedade marcada pela pouca circulação monetária, era natural que dinheiro, ações e títulos constituíssem um universo pouco acessível (ALMICO, 2001). Na verdade, o grupo social de que estamos tratando sempre solicitava crédito aos mais abonados, daí grande parte deles figurar no rol das dívidas passivas.

Por ora, é necessário enfatizar que, não raras vezes, os mais pobres se endividavam e, ao contraírem débitos, perdiam os únicos bens que possuíam. Essa pode ser considerada uma característica marcante do estrato social em questão: a instabilidade social e econômica, como também atestou Maria Luiza Oliveira (2015) em relação à cidade de São Paulo. Ser proprietário de um pequeno sítio, ou de um casebre no subúrbio, na primavera de um ano, não impedia tornar-se agregado ou jornaleiro no inverno da temporada seguinte. Muitos não tinham dinheiro nem para pagar as despesas/custas do inventário quando do falecimento de um parente. Assim como Manoel Bernardes da Cunha Cassão, outros advogados, procuradores e curadores assumiam essa tarefa, como pudemos averiguar ao longo desta pesquisa.

A classificação da sociedade em três estratos sociais - A, B e C - e o estudo da distribuição da riqueza indicaram a existência de uma sociedade heterogênea, economicamente desigual e culturalmente multifacetada. Se, em regra geral, é possível perceber uma similitude em relação aos membros de um mesmo grupo social (o que permitiu agregá-los em três categorias), por outro lado, se olharmos mais de perto, podemos identificar distinções significativas entre eles - desvios(?).

Tal diversidade material levou os membros de um mesmo grupo social a apresentar divergências e antagonismos quanto aos hábitos culturais, estilos e, consequentemente, quanto à natureza material dos bens e objetos pessoais que adquiriam em vida. $\mathrm{O}$ caso mais 
exemplar é o de Manoel Bernardes da Cunha Cassão, que veremos de forma verticalizada a seguir.

\section{Cultura material de um abolicionista no Vale do Paraopeba $(M G)$}

Em 1877, na "morada de casas sitas na rua das Flores envidraçada com seu competente quintal cercado de muro de barro, com outra casa no Pátio", não muito distante da Igreja do Senhor do Bonfim, o corpo do Sr. Manoel Bernardes da Cunha Cassão era velado. Além da viúva, o falecido deixava seis filhos: três meninos e três meninas, todos menores de 15 anos. Dona Libânea Luiza da Cunha Cassão não ficou em má situação econômica. Além da casa na rua das Flores, avaliada em mais de dois contos de réis, o marido ainda lhe havia deixado uma segunda moradia na mesma rua das Flores, avaliada pelos louvados em $600 \$ 000$. Três terrenos no valor de $330 \$ 000$ e três pastos, no valor de $380 \$ 000$, também compunham os $51,3 \%$ dos bens de raiz deixados em herança (Ver Tabela 2).

Conforme nos lembra Meneses (2007, p. 15), o inventário (nesse caso, o de Manoel Bernardes da Cunha Cassão) oferece "uma inflexão no circuito da vida social do artefato", lançando-se em outro ciclo, qual seja, o momento em que a vida de um dos cônjuges se esvai e a família precisa fazer o balanço material de toda uma existência. Neste momento, é da existência de Cassão que nos vamos ocupar, e não de sua morte. As informações que temos sobre esse homem estão contidas nas fontes cartorárias, sobretudo nos processos crimes em que atuou como testemunha, curador, procurador, advogado (e, como já mencionado, no seu inventário post-mortem). Muitas informações poderiam ser obtidas se tivéssemos acesso a seus registros de nascimento, casamento, óbito, cartas, certidões, escrituras etc.

Tabela 2:

Cultura material e intelectual de Manoel Bernardes da Cunha Cassão em 1877

\begin{tabular}{|l|c|c|}
\hline Tipologia dos Bens & Valores em réis & $\%$ \\
\hline Bens de raiz & 3.110 .000 & 51,30 \\
\hline Animal (possuía apenas cavalos) & 1.200 .000 & 16,60 \\
\hline Dívidas ativas (créditos a receber) & 1.285 .710 & 17,81 \\
\hline Estoque & 11.500 & 0,16 \\
\hline Indumentária geral & 8.000 & 0,11 \\
\hline Joias & 3.000 & 0,04 \\
\hline Livros & 251.000 & 3,48 \\
\hline Mobiliário & 320.000 & 4,43 \\
\hline
\end{tabular}




\begin{tabular}{|l|c|c|} 
Outros gerais & 34.500 & 0,48 \\
\hline Outros pessoais & 274.500 & 3,80 \\
\hline Utensílios domésticos & 82.200 & 1,14 \\
\hline Utensílios profissionais & 46.700 & 0,65 \\
\hline Total do monte-mor & $\mathbf{7 : 2 2 3 . 7 7 8}$ & $\mathbf{1 0 0}$ \\
\hline
\end{tabular}

Fonte: AMB/MG, inventário post-mortem, CSO 17(21), 1877.

Ainda que incompletas, as informações e as pistas disponíveis permitem compor um quadro detalhado da vida de Cassão. Os pormenores desse quadro - ou melhor, desse mapa em escala reduzida - indicam, mesmo que de forma fragmentada, não só aspectos importantes de sua existência, mas principalmente a relação que esse homem teve com seu pares, com a política e com a sociedade vigentes na segunda metade do século XIX. Apropriamo-nos aqui do oxímoro - "excepcional normal", proposto por Edoardo Grendi para pensar a atuação social de Cassão e como ele, à primeira vista, poderia ser considerado um "desvio". Segundo Jacques Revel, a ideia de "excepcional normal" permite

[...] construir modelos "genéricos", ou seja, modelos que permitam integrar completamente (e não mais como exceções ou desvios) os percursos e as escolhas individuais. Nesse sentido, poder-se-ia dizer que o "excepcional" se tornaria "normal". (REVEL, 1998, p. 33).

Cassão, a personagem principal deste escrito, com seu inventário post-mortem, constitui exemplo modelar do que viria a ser um homem "excepcional normal", de acordo com a concepção proposta por Edoardo Grendi. A cultura material e intelectual acumulada em vida o assinala e o diferencia das centenas de documentos analisados no Banco de Dados. Como membro do Grupo B, ele foge ao padrão dos dados estatísticos. Mesmo se o compararmos ao estrato mais privilegiado da sociedade, o Grupo A, ainda assim Manoel Bernardes apresenta distinções e singularidades no que tange à posse (ou não) de determinados bens e objetos.

Após aferir a cultura material encontrada no inventário, poderíamos, então, considerá-lo um desvio, se tomarmos como referência a regra, o padrão vigente naquela sociedade? Para a compreensão dessa problemática, vamos focalizar de perto, ${ }^{21}$ além da cultura material, a ação profissional de Cassão.

\footnotetext{
${ }^{21}$ Manoel Luiz Salgado Guimarães (1998, p. 220) salienta que "na verdade, o que está em jogo pelo par de oposições macro e micro, segundo as perspectivas esposadas pelos autores do livro 'Jogos de Escalas: a experiência da microanálise' não é apenas uma mera diferença de escala tomada para a análise dos fenômenos históricos, mas um redimensionamento de objetos e questões que põem em dúvida a perspectiva da macroestrutura".
} 
Em 1858 e 1859, Manoel Bernardes já aparecia nas fontes cartorárias como advogado do Sr. Joaquim Nunes de Araújo e do Sr. Feles Pereira da Rocha. ${ }^{22}$ Nos dois inventários citados, os bens materiais eram de "pouca monta" e a avaliação do patrimônio mal dava para pagar as custas dos processos. É interessante observar que, dentre a centena de livros que o advogado possuía, destacam-se o Novo Advogado do Povo e o Advogado Comercial. Certamente ficavam na "estante grande para livros", ao lado da Consulta Jurídica, do Direito Penal, do Código do Processo Criminal e outras tantas obras lidas e examinadas pelo advogado ao longo de sua vida, em Bonfim do Paraopeba. ${ }^{23}$

Alguns anos se passaram e, em 1873, Manoel Bernardes assumiu o cargo de "Solicitador de Capellas e Resíduos"24 do Município de Bonfim. Segundo Costa,

O posto de provedor das Fazendas de Defuntos e Ausentes, Capelas e Resíduos era ocupado pelo ouvidor da comarca, um magistrado, isto é, um agente letrado nomeado e provido diretamente pelo Rei para exercer a justiça em segunda instância. Além do cargo de provedor, havia o tesoureiro de ausentes, o escrivão de ausentes, o solicitador dos resíduos, o meirinho de ausentes e o escrivão do meirinho de ausentes. (COSTA, 2015, p. 1, grifos nossos).

Ainda segundo o autor mencionado, o Solicitador de Resíduos e Capelas tinha como função dar início às causas da provedoria. Era sua responsabilidade notificar as pessoas para fazer a entrega de testamentos, apresentar as contas de testamento, assinar termo de aceitação ou desistência da testamentária, convocar os

[...] tutores para dar conta dos rendimentos e despesas da herança dos menores, notificar as pessoas para proceder na partilha dos bens ou remir penhores, uma vez que o cofre do Juízo de Ausentes (assim como o Juízo dos Órfãos) funcionava, por vezes, como verdadeira instituição de crédito. (COSTA, 2015, p. 2).

\footnotetext{
${ }^{22}$ Arquivo Municipal de Bonfim/Minas Gerais, Inventário post mortem, CPO 07 (8), 1858, e CPO 73 (15), 1849.

${ }^{23}$ Todos os nomes e nomenclaturas de objetos, livros e bens materiais mencionados foram retirados das fontes cartorárias exploradas neste artigo.

${ }^{24}$ Ver Almanaque Administrativo, Civil e Industrial de Minas Gerais, em 1873.
} 
Como se pode perceber, Cassão estava também envolvido com a partilha das propriedades. Zelava pelo patrimônio dos ausentes, além de ter conhecimento pleno dos leilões dos bens móveis e imóveis dos cidadãos do Município. O "Livro que trata dos Bens dos Defuntos e Ausentes", encontrado no inventário de Cassão, sugere que se dedicava ao assunto e ao cargo ocupado na Administração Jurídica.

No entanto, de todos os casos em que esteve envolvido, o que mais chama atenção é o processo crime no qual atuou como advogado e curador de um escravo. ${ }^{25} \mathrm{Em} \mathrm{1875}$, o réu escravo de nome Rofino teve sua sentença de morte comutada para prisão perpétua a pedido do curador, o Dr. Manoel Bernardes da Cunha Cassão. A história descrita no processo crime é digna de nota, como se pode averiguar na descrição do referido processo crime.

Tendo o referido Rofino por costume cavalgar, as noites, os próprios animais do Suplicante para suas correrias e vadiações, foi assim que, o romper do dia 05 do corrente mês, levantando-se o filho do suplicante, João Ribeiro Diniz, esse por falta, não só do dito escravo, como do cavalo, pertencente a mulher do suplicante; e, pois, seguindo ele por os lados que costumava passear, ou vadiar o dito crioulo Rofino, o encontrara ao chegar na porteira do pasto da fazenda do Suplicante, que só pelo facto de ser assim encontrado por seo senhor moço, apeou-se do cavalo, acommette-o com uma faca e o assassinou, torturando-o, como se vê do Corpo de Delicto. Tão audás é o acusado que, praticando o fato criminoso, evade-se e sobranceiramente vem apresentar à Justiça desta Cidade, solicitando sua entrada para a cadea e vangloriando-se do que fez. (PROCESSO CRIME, CSO 29 (565).

A descrição do delito criminoso permite refletir sobre várias questões relativas ao sistema escravista, principalmente quando este já estava fadado ao término, em virtude da promulgação da Lei que proibia definitivamente o tráfico negreiro (1850), da Lei do Ventre Livre (1873) etc. Interessa-nos, aqui, analisar, particularmente, a atuação e a mediação de Cassão no referido processo. Por isso, destaque também deve ser dado à sentença pronunciada em 18 de janeiro de 1877 (coincidentemente sete meses antes da morte do mencionado curador).

\footnotetext{
${ }^{25}$ Arquivo Municipal de Bonfim/Minas Gerais, Processo Crime, CSO 29 (565).
} 
A Princesa Imperial Regente, em nome de Sua Majestade o Imperador o Senhor Dom Pedro Segundo, usando da atribuição conferida no artigo cento e um, paragrapho oitavo da Constituição do Império e de conformidade com o parecer da Secção de Justiça do Conselho do Estado, vê por bem comutar em galês perpétua a pena de morte imposta em virtude de decisão do Jury do termo do Bonfim, na Província de Minas Geraes, ao réo escravo Rofino, por crime de homicídio.

Diogo Velho Cavalganti de Albuquerque, do Conselho do Mesmo Augusto Senhor, Ministro e Secretário de Estado dos Negócios da Justiça, assim o tenha entendido e faça executar. (PROCESSO CRIME, CSO 29 (565).

Assinada e despachada do Palácio da Justiça na Corte do Rio de Janeiro, a sentença promulgada pela Princesa Isabel aponta algumas questões. A interferência da herdeira de Dom Pedro II nos assuntos ligados à escravatura fazia parte de uma estratégia de desmantelamento do sistema compulsório. ${ }^{26}$ As fontes não permitem dizer, nem atribuir a Cassão influência junto à Corte Imperial, muito menos que tinha alguma relação ou contato direto com a Princesa Isabel. Mas esse fato, associado a outros em que interferia em prol dos escravos, permite presumir que esse homem não só advogava em defesa dos cativos, mas que também não compartilhava dos ideais escravistas.

As informações e elementos encontrados no seu inventário endossam a problemática levantada. Ao examinar figurativamente "as estantes para guardar livros", deparamo-nos com três volumes emblemáticos: Acadêmicas por mente negra, "Novo Advogado do Povo e Livro de Gestos do Brasileiro. Além dessas obras, podem-se encontrar ainda dezenas de títulos sobre História Universal, História da Revolução Francesa, História dos Girondinos etc. Os livros indicam que Cassão não apenas se preocupava com as causas sociais e étnicas, mas que também possuía erudição, ideias e opiniões sobre as demais nações, costumes, hábitos e "gentes".

Outro fato digno de nota no inventário post-mortem: além de não haver escravos entre os bens arrolados, alude-se aos "serviços de um escravo Bernardino por um estado de 28 meses no valor de 466 \$668" e aos "serviços de um escravo Faustino no valor de $130 \$ \$ 000$ ". A remuneração pelos trabalhos prestados por esses indivíduos não só reforça o pressuposto de que a família Cassão não possuía escravos e ainda pagava pelas tarefas executadas. Entretanto, não ficou claro de quem eram os dois cativos que Cassão remunerava. No

${ }^{26} \mathrm{O}$ debate historiográfico a respeito da crise do sistema escravista consolidou-se no Brasil, especialmente, a partir da década de 1980. A título de referência ver, sobretudo, os trabalhos de Robert Conrad (1978), Emília Viotti da Costa (2008), Ciro Flamarion Cardoso (1988), Sidney Challoub (1990) e Hebe Maria Mattos de Castro (1998). 
documento cartorário, como já mencionado, não foi localizado nenhum escravo, muito menos a informação sobre alforrias, ou algo semelhante.

Todos os indícios sugerem que Manoel Bernardes não possuía cativos por uma opção pessoal - poderíamos arriscar a dizer "ideológica"? A riqueza acumulada em vida (mais de sete contos de réis) permitiria a ele ser proprietário de um plantel de até seis escravos, como de fato acontecia com os membros do Grupo B ao qual pertencia. Alguns objetos encontrados na casa desse homem oitocentista sinalizam que ele se preocupava com assuntos e interesses distintos, deles ocupando-se.

A "mala de viagem" e o "copo de vidro de viagem", avaliados em 11\$000 réis, indicam que Cassão circulava dentro e fora da Província de Minas Gerais. É importante destacar que, no século XIX, o Vale do Paraopeba constituiu uma importante zona de abastecimento interno. A produção de alimentos era comercializada em várias partes da Província de Minas Gerais, assim como na Corte do Rio de Janeiro (MARTINEZ, 2014). A centena de livros, a flauta, o flautim, o piano, o relógio de parede com caixa, os quadros de retratos, o espelho grande dourado, o tapete aveludado, o mobiliário sofisticadíssimo, as cadeiras de palhinha, as cadeiras finas e novas, as canastras, as marquesas, a mesa de jantar, as estantes para guardar livros, as cômodas, as cantoneiras de mármore, o tinteiro de cristal, as duas máquinas de bater ovos, a máquina de fazer água gasosa e tantos objetos do cotidiano certamente faziam da casa de Dona Libânea, esposa de Cassão, um lar que se distinguia, em muito, do de seus vizinhos na rua das Flores.

Ao lado de tantos objetos distintos, ousados e exóticos, encontramos outros artefatos que situam Cassão no "tempo" e em seu "lugar". O bote para pescar, a bolsa de caçador, as armas (pistola de dois canos, chicote de cabo de metal, canivetes, facão aparelhado de prata), a munição (quinze livras de chumbo) e o couro de ariranha nos fazem pensar nas noites em que passava caçando tatus, tamanduás, porcos-espinhos, cutias - animais hoje praticamente extintos na região do Vale do Paraopeba. A caça, no século XIX, constituía atividade de lazer e diversão, destinada, principalmente, aos mais abastados, os quais costumavam praticá-la tendo como instrumento e proteção armas, cães e cavalos. Cassão, nesse quesito, não fugiu à regra.

Do mesmo modo, deve-se mencionar que quase $18 \%$ de seu patrimônio estavam assentados em Dívidas Ativas (créditos), índice que supera as cifras relativas aos artefatos $(14,3 \%)$ e aos cavalos (16,6\%), conforme mostra a Tabela 2 . Vivendo dos serviços prestados como advogado, era natural ter dinheiro a receber de seus conterrâneos. Tal situação nos remete ao início deste artigo. As atitudes de Manoel Bernardes da Cunha Cassão, sua atuação social, seus bens e artefatos tornavam-no um homem "excepcional normal"?

Em relação ao conceito "excepcional normal", Sandra Pesavento (2004, p. 180) nos apresenta dois enfoques distintos, mas que se complementam: "o do registro só 
aparentemente excepcional, mas que constitui uma prática vulgar na cotidianidade da vida" ou "de que justamente o excepcional, a transgressão, a marginalidade e o desvio podem dar conta da norma".

As informações extraídas das fontes e documentos não deixam dúvidas de que Manoel foi um homem extraordinário, no sentido de dessemelhante da maioria de seus pares. Possuir escravos, terras e propriedades era fundamental para um indivíduo estabelecer-se como um "homem bom" na sociedade, na economia e na política imperial - no caso específico, em Bonfim do Paraopeba (MATTOS, 2004). Ao mesmo tempo, essa mesma sociedade demandava a (co)existência de homens como Cassão, para lecionar, regular contratos, dar assistência jurídica aos mais pobres, fiscalizar o patrimônio dos ausentes e das obras das capelas e igrejas, fazer a partilha das grandes fortunas, defender escravos e denunciar as mazelas sociais...

A cultura material, o comportamento e os hábitos singulares de Cassão permitem compreender como funcionava a norma, evidenciando as regras e os padrões vigentes. Embora em menor número, indivíduos "excepcionais", como Cassão - difíceis de serem mensurados em análises quantitativas -, compunham de forma exemplar o jogo da vida, das fortunas e das ideias oitocentistas.

Por fim, cabe sublinhar que os significados simbólicos da cultura material, bem como a atuação social, jurídica e política de Manoel Bernardes, reportam ao peculiar personagem Jacques Fournier, do mestre Emmanuel Le Roy Ladurie (1997, p. 19): "Maníaco do detalhe, ilumina, além das crenças e dos desvios, a própria vida da comunidade".

\section{Referências}

\section{Fontes}

- Almanaque Administrativo, Civil e Industrial de Minas Gerais, 1873.

- Arquivo Municipal de Bonfim/MG, Inventário post-mortem, CSO, 17(21), 1877.

- Arquivo Municipal de Bonfim/Minas Gerais, Processo Crime, CSO 12 (277), 1858.

- Arquivo Municipal de Bonfim/Minas Gerais, Inventário post-mortem, CPO 07 (8), 1858 e CPO 73 (15), 1859.

- Arquivo Municipal de Bonfim/Minas Gerais, Processo Crime, CSO 29 (565), 1875.

- Arquivo Municipal de Bonfim/MG, Inventário post-mortem, CSO, 20(12), 1866. 
- Arquivo Municipal de Bonfim/MG, Inventários post-mortem, CSO, 65(10), 1893; CSO 19(06), 1895; CSO 65(07), 1890.

\section{Bibliografia}

AMILCO, Rita de Cássia da Silva. Fortunas em Movimento: um estudo sobre as transformações na Riqueza Pessoal em Juiz de Fora: 1870-1914. (Dissertação de Mestrado). IE/UNICAMP, 2001.

ARAÚJO, Maria Lucília Viveiros. Os Caminhos da Riqueza dos Paulistanos na primeira metade do Oitocentos.(Tese de Doutorado). São Paulo: Universidade de São Paulo, Departamento de História, 2003.

BARROSO, Gustavo. Classificação geral de móveis antigos. In: Anais do Museu Histórico Nacional. Rio de Janeiro: Imprensa Nacional. v. 4, 1947, p. 558-601.

CARDOSO, Ciro Flamarion. (Org.). Escravidão e Abolição no Brasil: novas Perspectivas. Rio de Janeiro: Jorge Zahar Editor, 1988.

CASTRO, Hebe Maria Mattos de. Das cores do silêncio: os significados da liberdade no sudeste escravista. Brasil, século XIX. Rio de Janeiro: Nova Fronteira, 1998.

CHALLOUB, Sidney. Uma história das últimas décadas da escravidão na Corte. São Paulo: Companhia das Letras, 1990.

COSTA, Emília Viotti da. A abolição. (8ª edição revista e ampliada). São Paulo: Editora Unesp, 2008. (1. ed. 1982).

COSTA, Wellington Júnior Guimarães da. Das desordens na Provedoria de Defuntos e Ausentes, Capelas e Resíduos na América Portuguesa. Anais do XXVIII Simpósio Nacional de História. Florianópolis: ANPUH, 2016.

CONRAD, Robert. Os últimos anos da escravatura no Brasil. Rio de Janeiro: Civilização Brasileira, 1978.

FRAGOSO, João Luís Ribeiro. Homens de grossa aventura: acumulação e riqueza na praça mercantil do Rio de Janeiro (1790-1830). Rio de Janeiro: Arquivo Nacional, 1992. 
FREYRE, Gilberto. Casa Grande e Senzala: formação da família brasileira sob o regime da economia patriarcal. 20. ed. Rio de Janeiro: Livraria José Olympio, 1980. (1. ed. 1933).

FREYRE, Gilberto. Sobrados e Mocambos: decadência do patriarcado rural e desenvolvimento do urbano. 9. ed. Rio de Janeiro: Record, 1996. (1. ed. 1936).

GINZBURG, Carlo Mitos, emblemas e sinais. São Paulo: Companhia das Letras, 1989.

GRENDI, Edoardo. Repensar a micro-história? In: REVEL, Jacques. Jogos de Escala. Rio de Janeiro: Editora Fundação Getúlio Vargas, 1998. p. 259.

GUIMARÃES, Manoel Luiz Salgado. Micro-história: reconstruindo o campo de possibilidades. In: Topoi, Rio de Janeiro, n. 1, p. 217-233.

HOLANDA, Sérgio Buarque de. Caminhos e Fronteiras. 3. ed. São Paulo: Companhia das Letras, 1994. (1. ed.1957).

LE ROY LADURIE, Emmanuel. Montaillou. Povoado Occitânico. Trad. Maria Lúcia Machado. São Paulo: Companhia das Letras, 1997.

LINHARES, Maria Yedda Leite. Metodologia da história quantitativa: balanço e perspectivas. In: BOTELHO, Tarcísio; MARQUES, Cláudia Eliane Parreiras et al. História Quantitativa e Serial: um balanço. Goiânia: ANPUH-GO, 2001.

MARTINEZ, Cláudia Eliane Parreiras Marques. Cinzas do Passado: cultura material, riqueza e escravidão no Vale do Paraopeba/MG (1831-1914). Londrina: EDUEL, 2014.

MARTINEZ, Cláudia Eliane Parreiras Marques. Riqueza e Escravidão: vida material e população no século XIX. Bonfim/MG. São Paulo: Annablume; FAPESP, 2007.

MATTOS, Ilmar Rohloff de. O Tempo Saquarema. 5. ed. São Paulo: Hucitec, 2004.

MATtoso, Kátia M. de Queirós. Bahia, Século XIX: uma província no Império. Rio de Janeiro: Nova Fronteira, 1992.

MENESES, Ulpiano Toledo Bezerra de. Apresentação da Nova Série. In: Anais do Museu Paulista: História e Cultura Material. São Paulo. N. Ser. N. 1. jan/dez. 1993. p. 5-7.

MENESES. Ulpiano Toledo Bezerra de. Apresentação do livro. In: MARTINEZ, Cláudia Eliane Parreiras Marques. Riqueza e Escravidão: vida material e população no século XIX.

Bonfim/MG. São Paulo: Annablume; FAPESP, 2007.

OLIVEIRA, Maria Luiza Ferreira de. Entre a casa e o armazém: relações sociais e experiências da urbanização - São Paulo, 1870-1900. São Paulo: Alameda, 2005. 


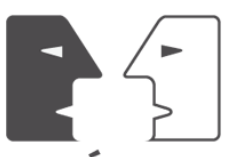

ANTÍTESES

PESAVENTO, Sandra. O corpo e a alma do mundo: a micro-história e a construção do passado. História Unisinos, v. 8, n. 10, jul/dez, 2004, p. 180.

REVEL, Jacques. Jogos de Escala. Rio de Janeiro: Editora Fundação Getúlio Vargas, 1998.

SAINT-HILAIRE, Auguste. Viagens pelas Provincias do Rio de Janeiro e de Minas Gerais. Belo Horizonte: Itatiaia; São Paulo: EDUSP, 1975.

VERSIANI, Flávio Rabelo; VERGOLINO, José Raimundo Oliveira. Posse de Escravos e Estrutura da Riqueza no Agreste e no Sertão Pernambucano: 1777-1887. Estudos Econômicos. v. 33, n. 2, 2003. 


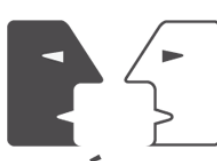

ANTÍTESES

Anexo 1

Gráfico 1:

Distribuição da riqueza por grupos sociais 1840 -

1849

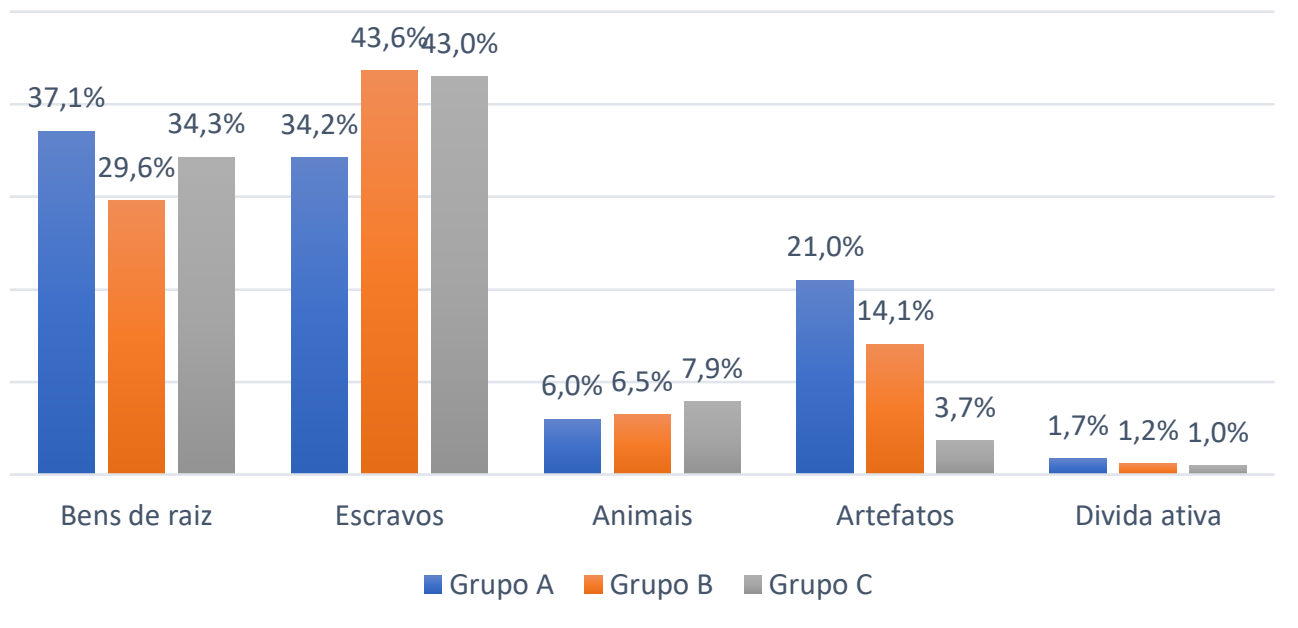

Gráfico 2:

Distribuição da riqueza por grupos sociais 1850 - 1859

$48,7 \%$

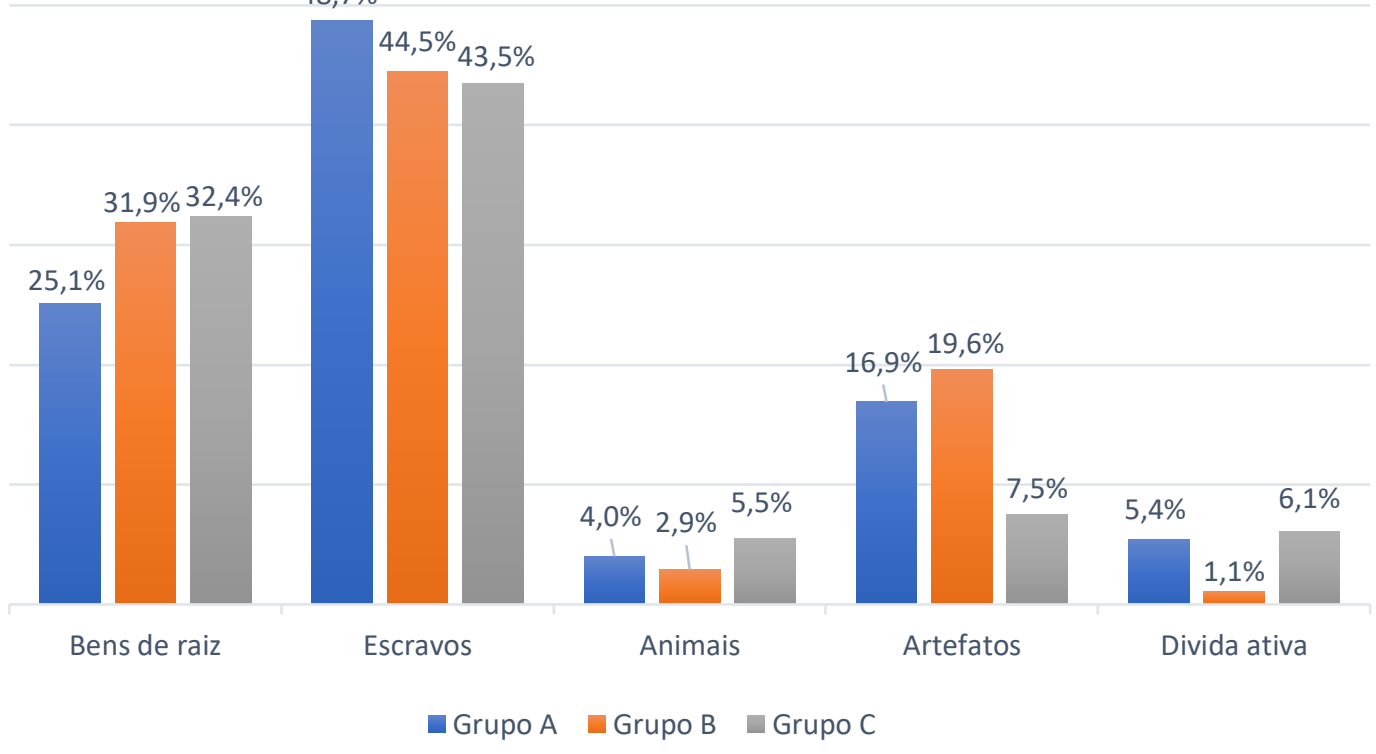




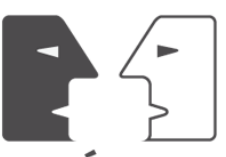

ANTÍTESES

\section{Gráfico3:}

\section{Distribuição da riqueza por grupos sociais 1860 - 1869}

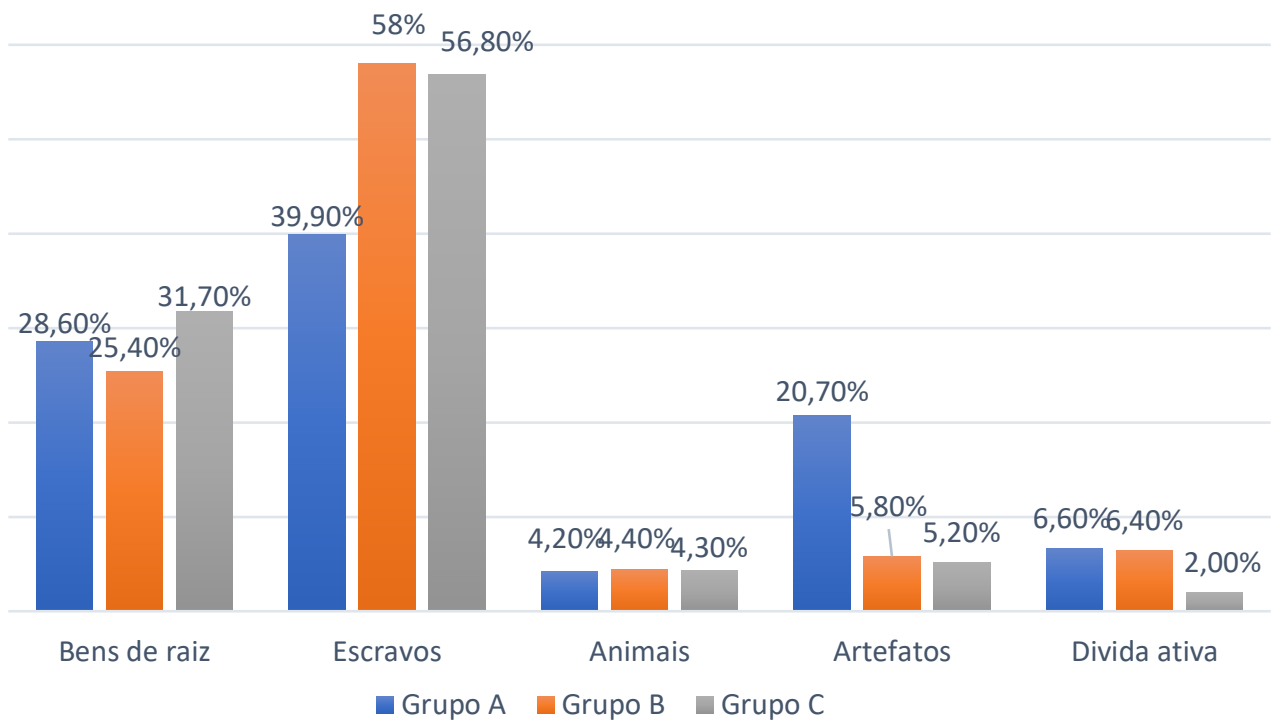

Gráfico 4:

Distribuição da riqueza por grupos sociais 1870 - 1879

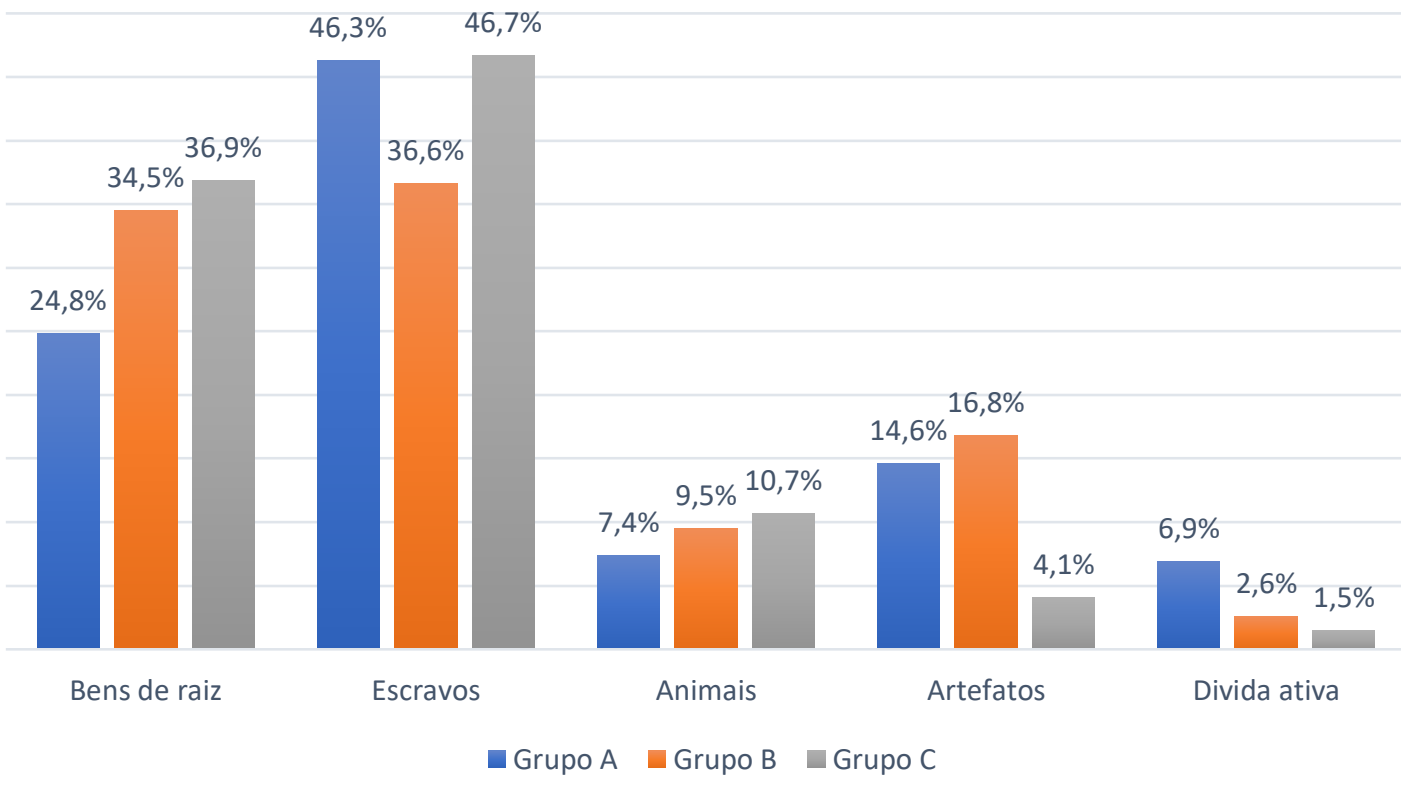




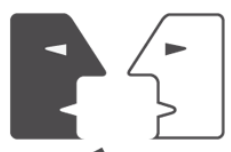

ANTÍTESES

\section{Gráfico 5:}

\section{Distribuição da riqueza por grupos sociais 1880 - 1888}

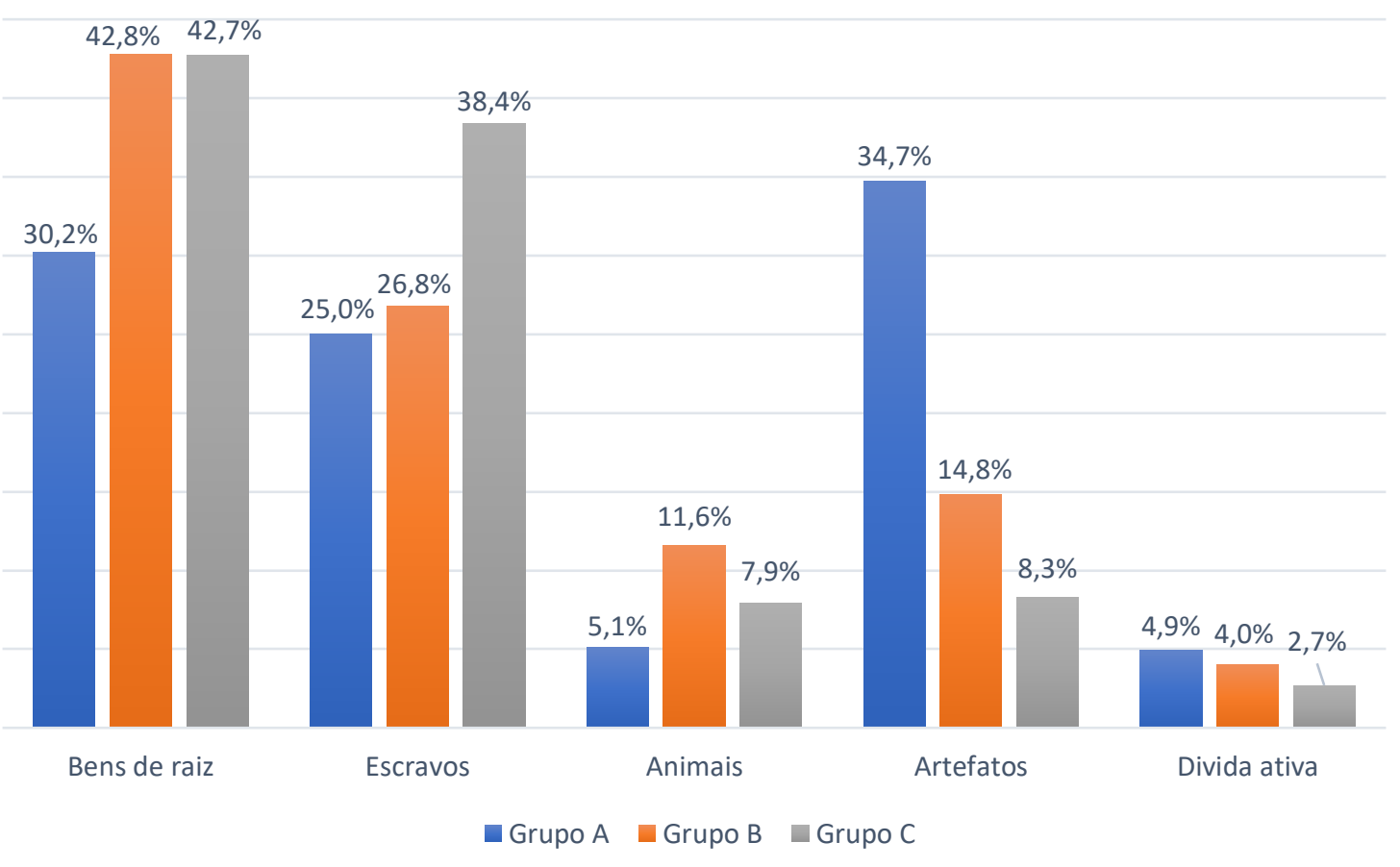

Recebido em: 30-05-2017

Aceito em: 24-08-2017 